\section{Improving public health by more effectively regulating tobacco products}

Key words: tobacco, smoking, health policy, regulation, legislation.

\footnotetext{
1 Based on: World Health Organization. Advancing knowledge on regulating tobacco products. Geneva: $\mathrm{WHO} ; 2001$. Available from: http:/ / tobacco.who.int [Internet site]. Accessed 15 January 2002.
}

Tobacco now kills some 4 million people a year around the world. Over the next three decades, that toll is expected to climb to some 10 million persons per year, with more than $70 \%$ of those deaths occurring in developing countries.

To help stem that increasing mortality, the World Health Organization (WHO) and its Member States have taken a number of steps. One area of focus has been the need for more effective regulation of tobacco products. This document summarizes some of the major themes from a recent $\mathrm{WHO}$ monograph entitled "Advancing Knowledge on Regulating Tobacco Products." That report, in turn, recaps much of the information presented and discussed at a WHO conference on tobacco products that was held in Oslo, Norway, in February 2000. The WHO monograph identifies deficiencies in current efforts to regulate tobacco products, and it also recommends actions that governments and others should take to remedy the underregulation of cigarettes and other tobacco products.

\section{REGULATORY ISSUES}

Numerous consumer products are regulated, including medications, manufactured food products, beverages, household devices, and automobiles. There are two goals for such regulation: to facilitate fair commercial trade and marketing, and to protect people from undue risk of harm caused by the products. Product regulation can also contribute to the evolution of better products.

Nevertheless, it is increasingly apparent that the regulation of tobacco products is severely lacking. Deficiencies in tobacco regulations have fostered trade and marketing practices that are not allowed for other products and have also contributed to growing addiction among young people. Cigarette smuggling is widespread. Tobacco companies have developed product marketing campaigns for imported cigarettes that bypass the collection of customs duties. Cigarettes are designed so that consumers obtain higher levels of toxin exposure than are indicated on the products' package labels. Marketing claims that imply health benefits and reduced risk, with terms such as "light" or "low-tar," are routinely made in advertisements and even in many cigarette brand names, without any evidence that the products provide those benefits (see the 
sidebar entitled "No health benefit from low-tar cigarettes").

Many areas of tobacco product regulation could be reformed so as to develop regulatory approaches that would be consistent with public health goals and thereby contribute to reducing tobacco-attributable disease.

Product regulation, however, is just one aspect of the overall drive to reduce the tobacco epidemic. The context is of a range of efforts to reduce tobacco consumption such as by regulating access and by limiting demand through higher taxation and restrictions on advertising, marketing, promotion, and distribution.

Governments need to have relevant, accurate, and current scientific information about the toxic substances in tobacco products and tobacco smoke. Governments also should help smokers and nonsmokers make more informed decisions regarding the use of tobacco.

There are variations in the regulation of different nicotine-delivering devices. This has resulted in what some experts call a "nicotine maintenance monopoly," with the deadliest products having the greatest regulatory advantages. This distorts markets in favor of continued high levels of mortality and morbidity. Novel products, even those offering unequivocal health benefits compared to existing tobacco products, are often effectively banned from the marketplace due to burdensome regulatory standards.

\section{Outdated measurement techniques}

Existing regulatory structures are based on scientific information that is now out of date. For instance, "tar" has generally been accepted as the major carcinogenic component of cigarette smoke. Reductions in cigarette tar levels were therefore seen as a form of product modification that could reduce harm. It was also assumed that the tar yields printed on a product package approximately represented the tar exposure to the smoker. However, researchers have pointed out that these assumptions are false, yet that they continue to inform policy on tobacco product regulation.

The tar and nicotine levels are measured by machines using an approach developed by the Federal Trade Commission of the United States of America and later adopted by the International Organization for Standardization. The test does not measure what consumers ingest from their cigarettes because people do not smoke like the test machines do. A better measurement of health impact might be the tar-to-nicotine ratio.

\section{Comprehensive disclosure}

An important prerequisite for developing more enlightened regulation is a comprehensive disclosure regime. Regulators need a detailed characterization of tobacco products in order to specify regulations that would result in meaningful improvements. This detailed disclosure should be distinguished from the consumer information made available on packs. Better disclosure would also support efforts to establish a common international strategy on tobacco product modification.

\section{New regulatory approaches}

There are wide differences between the measures that various countries have taken in their efforts to regulate tobacco as a product. Until recently, the most relevant legal instruments-ones to regulate consumer products and foodstuffs-have rarely been used. One possibility is for countries to legislate their rights to verify the content of tobacco and smoke, to inspect production sites, to limit the amount of certain ingredients, and to approve additives. Governments can also request the declaration of certain additives, the purpose for their use, and a toxicological evaluation of them.

Linked to this could be a common international strategy on the future of product modification. An element of this would be the regulation of all nicotine delivery products within a common framework. Such a framework could establish common approaches to testing whether new product developments were in the public interest. It could encourage the production and marketing, for nicotine addicts, of less harmful forms of nicotine.

Since the establishment of an entirely new system of regulating nicotine products is unlikely, other researchers have suggested that one alternative might be a form of co-regulation. In such a system tobacco products and novel products could be regulated separately, but with the regulation of each taking into account the impact of the regulation of the other category of products. This could again be directed at attaining the greatest overall reduction in tobacco-related morbidity and mortality.

\section{Needed global responses}

The working groups at the WHO February 2000 Oslo conference proposed various proactive global responses that should be part of a regulatory framework for tobacco products. For example, global capacity within the public sector is currently 


\section{No health benefit from low-tar cigarettes}

In the United States of America millions of persons smoke "low-tar," "mild," or "light" cigarettes in the belief that such cigarettes are less harmful than other, regular cigarettes. Nevertheless, in a new monograph from the National Cancer Institute (NCI) of the United States, scientific experts conclude there is no evidence that the public has benefited from these newer kinds of cigarettes.

Entitled Risks Associated with Smoking Cigarettes with Low Machine-Measured Yields of Tar and Nicotine, the report demonstrates that people who switch from regular cigarettes to low-tar or light cigarettes are likely to inhale the same amount of cancer-causing toxins. Those smokers also remain at high risk for developing smoking-related cancers and other diseases.

Epidemiologic studies in the 1960s and 1970s found that smokers of lower-tar or filtered cigarettes had somewhat lower lung cancer risks than did smokers of other types of cigarettes. It was predicted that as more smokers used lower-yield products for longer periods of time, a greater benefit would occur and national lung cancer death rates would fall.

Unfortunately, these reductions have not been seen. Even as the popularity of supposedly loweryield cigarettes grew, lung cancer rates continued to rise until the early 1990s. The NCI monograph demonstrates that the overall decline that has been seen in lung cancer rates since the 1990 s can be attributed to the decrease in smoking prevalence, and not to changes in cigarette design.

The new report reviews the scientific literature on death rates in the United Kingdom and in the United States. Those studies demonstrate that there was an increase-rather than a decrease-in smoking risks over a period of time when machine-measured yields of tar and nicotine were declining.
The NCI monograph describes several reasons why the levels of tar and nicotine as measured by the standard method of the Federal Trade Commission of the United States do not reflect actual tar and nicotine delivery to the smoker. The filters in low-tar/lownicotine cigarettes often include vent holes that, when open, allow air to enter and dilute the smoke. However, many smokers cover these holes with their lips and fingers. In contrast, when tested by a machine, the holes are unobstructed, and artificially low measurements of tar and nicotine result. In addition, smokers who switch to low-tar or low-nicotine cigarettes from regular cigarettes "compensate" for the lower nicotine level by inhaling more deeply; by taking larger, more rapid, or more frequent puffs; or by increasing the number of cigarettes smoked per day. As a result, smokers cancel out any potential benefit of smoking "low-tar" cigarettes.

Surveys have indicated that among the estimated 47 million adults who smoke in the United States, people who are most concerned about smoking risks or are most interested in quitting use brands labeled "light" or "ultralight." However, there is no evidence that switching to such cigarettes actually helps smokers to quit. The central message of the new NCI monograph is that the only proven way to reduce the disease risks associated with smoking is to quit.

Copies of the monograph are available for free. Persons in the United States can telephone tollfree to 1-800-422-6237 and ask for the report. Requests can also be sent by fax to 301-330-7968 or by mail to: National Cancer Institute, Publications Ordering Service, P.O. Box 24128, Baltimore, Maryland 21227, United States of America. The monograph can also be viewed and downloaded for free on the Internet from the NCI's Publications Locator Web site, at http://www.cancer.gov/publications. inadequate to understand technical aspects of tobacco product regulation. Urgent attention should be given to developing expert capacity within the tobacco control community on technical issues relating to product design, manufacture, and technology.

Clearinghouses for global knowledge on tobacco products are needed. They should maximize the use of information technology and draw on existing centers of excellence.

Reports that experts have prepared for their individual nations should be used globally. This is true, for instance, for studies done in the United States on a low-tar policy and on a methodology for assessing tobacco products. 
A wider range of strategic partners should be involved in product regulation development and implementation. This could include any group that is willing to advance public health goals. As examples, such partners may include printers, pharmaceutical companies, large companies with workforces trying to quit, "ethical" corporations, and consumer groups.

\section{Elements for the future regulation of tobacco products}

Many components are needed for a comprehensive set of tobacco product regulations. According to some researchers, the necessary elements include:

- establishing a new basis for measurement, regulation, and labeling of tobacco products

- regulating tobacco product additives

- requiring, by brand, full disclosure of such characteristics as nicotine content, the concentrations of known carcinogens and other toxins in smoke, and the tar/nicotine ratio; this information should be made public

- removing misleading "low-tar" or "light" branding unless a genuine evidence-based health benefit can be established by the company to the satisfaction of an appropriate regulatory agency

- removing misleading tar yield numbers that now commonly appear on product packages, and strengthening the warnings to consumers that appear on packs or in package inserts

- monitoring societal nicotine dependence such as by cross-sectional and cohort population surveys

\section{A new scientific advisory committee}

One of the recommendations that was made at the WHO's Oslo conference was to establish an international expert group on tobacco and nicotine delivery devices that would guide international policy development with respect to tobacco product regulation and that could facilitate access to scientific information needed for tobacco regulation. WHO established that expert group in March 2000. Called the Scientific Advisory Committee on Tobacco Product Regulation (SACTob), the group is working to catalogue existing regulations and the impact, if known, that these regulations have. All tobacco products are of concern to the Committee, but commercially manufactured cigarettes are a priority because they are projected to account for the vast majority of global deaths attributable to to- bacco for many decades to come in most countries of the world, especially in developing nations.

Some of the early SACTob meetings have been concerned with such specific issues as methods to more accurately test the contents of tobacco products, concerns over the misleading labeling of tobacco products as "light" or "mild," and the development of a common regulatory framework of such products. Other planned activities for SACTob include:

- assessing the impact of different tobacco regulatory frameworks existing within WHO Member States

- evaluating how regulatory approaches developed for cigarettes could be adapted to cover all forms of tobacco

- advising on regulating additives to tobacco products

- helping devise new methods to better measure the true impact of tobacco products on an individual and population basis

- determining if governments and international agencies could encourage the development of substantially less harmful tobacco products

- making recommendations on products for treating tobacco dependence

\section{SINOPSIS}

\section{Mejorar la salud pública a través de una regulación más eficaz de los productos del tabaco}

En la actualidad, el tabaco mata cada año a unos 4 millones de personas en todo el mundo. Se espera que esta cifra aumente a 10 millones de personas al año en las próximas tres décadas, y más del 70\% de estas muertes ocurrirán en países en desarrollo. La Organización Mundial de la Salud (OMS) y sus Estados Miembros han tomado una serie de medidas para contribuir a detener este aumento de la mortalidad. Uno de los aspectos analizados ha sido la necesidad de una regulación más eficaz de los productos del tabaco. Este documento resume algunos de los principales temas de una monografía reciente de la OMS acerca de este problema, en la que se recapitula gran parte de la información presentada $y$ discutida en la conferencia de la OMS sobre productos del tabaco que tuvo lugar en Oslo, Noruega, en febrero de 2000. La monografía identifica las deficiencias de las actuales regulaciones sobre los cigarrillos y otros productos del tabaco y contiene recomendaciones acerca de las acciones que los gobiernos y otras autoridades deberían adoptar para remediar dichas deficiencias. 